\title{
Examining the accumulated oxygen deficit method in breaststroke swimming
}

\author{
Victor Machado Reis • Daniel Almeida Marinho • \\ Fernando Policarpo Barbosa • António Malvas Reis • \\ Laura Guidetti · António José Silva
}

Accepted: 24 March 2010/Published online: 7 April 2010

(C) Springer-Verlag 2010

\begin{abstract}
The present study investigated the accumulated oxygen deficit (AOD) method in breaststroke swimming with the aims to assess the reliability of the oxygen uptake/ swimming velocity regression line and to quantify the precision of the AOD. Sixteen male swimmers performed two swimming tests in different days, with a 24-h recovery between tests: a graded swimming test and an all-out test. The all-out test was performed in one of two distances: $100 \mathrm{~m}(n=7)$ or $200 \mathrm{~m}(n=9)$. Through all testing, expired gases were collected breath by breath and analysed with a K4b2 Gas Analyser (Cosmed, Rome, Italy) connected to an AquaTrainer Valve (Cosmed, Rome, Italy). The standard error of the regression lines was $\approx 5-6 \mathrm{ml}$ $\mathrm{kg}^{-1} \min ^{-1}$ and the regressions allowed an extrapolation of the energy cost to higher intensities with a standard error of the predicted value that was lower in the 200-m
\end{abstract}

Communicated by Susan Ward.

V. M. Reis $(\bowtie)$ F. P. Barbosa · A. M. Reis · A. J. Silva Department of Sport Sciences, Exercise and Health, University of Trás-os-Montes and Alto Douro (UTAD), Rua Dr. Manuel Cardona/CIFOP, 5000-558 Vila Real, Portugal

e-mail: vreis@utad.pt

V. M. Reis · D. A. Marinho · F. P. Barbosa ·

A. M. Reis - A. J. Silva

Research Centre in Sport Health and Human Development (CIDESD), Vila Real, Portugal

D. A. Marinho

Department of Sport Sciences, University of Beira Interior (UBI), Covilhã, Portugal

L. Guidetti

University Institute of Motor Sciences (IUSM), Rome, Italy bout $\left(\approx 3.5 \mathrm{ml} \mathrm{kg}^{-1} \mathrm{~min}^{-1}\right)$ comparatively to the $100-\mathrm{m}$ bout $\left(\approx 6 \mathrm{ml} \mathrm{kg}^{-1} \mathrm{~min}^{-1}\right)$. The AOD imprecision was calculated as the square root of the sum of the oxygen uptake measurement error and the standard error of the predicted value for energy cost. AOD imprecision was smaller in the 200 -m bout $\left(\approx 9 \mathrm{ml} \mathrm{kg}^{-1} \mathrm{~min}^{-1}\right)$ comparatively to the 100 -m bout $\left(\approx 12 \mathrm{ml} \mathrm{kg}^{-1} \mathrm{~min}^{-1}\right)$. However, since the AOD values during the two distances were small, the AOD relative errors can be viewed as high. Additionally, the data variability was considerable (95\% confidence intervals of the linear extrapolation larger than $20 \mathrm{ml} \mathrm{kg}{ }^{-1} \min ^{-1}$ ).

Keywords Breaststroke swimming . Accumulated oxygen deficit · Precision

\section{Introduction}

The energy cost of swimming $\left(C_{\mathrm{S}}\right)$ can be assessed as the ratio between $\mathrm{O}_{2}$ uptake $\left(\dot{V} \mathrm{O}_{2}\right)$ and the corresponding swimming speed. A previous study reported that $C_{\mathrm{S}}$ may be described as a linear function of the speed (Barbosa et al. 2006). During high exercise intensities it is necessary to combine estimations from aerobic and anaerobic energy release to assess $C_{\mathrm{S}}$. The aerobic energy is simply calculated from the $\dot{V} \mathrm{O}_{2}$ energy equivalent, but the anaerobic energy release requires indirect estimations. The most common procedure to assess anaerobic energy release is to use the values resulting from the transformation of net peak lactate accumulation into $\mathrm{O}_{2}$ equivalents (diPrampero et al. 1978; Zamparo et al. 2000). Another potential indirect quantification of anaerobic energy release during highintensity exercise is the estimation of the accumulated oxygen deficit (AOD). 
Medbø et al. (1988) were the first to present a detailed study on the precision of the AOD estimation for treadmill running. Others have subsequently assessed the reliability of the method by the precision of the supramaximal energy demand prediction error (Russell et al. 2000,2002 ) or by the precision of the AOD itself (Reis et al. 2005). This method proved accurate in running (Reis et al. 2005) and cycling (Russell et al. 2000, 2002) exercise, among others, and has been extensively used in laboratory (Bickham et al. 2002; Russell et al. 2002) as well as in field testing (Duffield et al. 2004; Reis et al. 2004).

Hence, the AOD seems a potential approach that can be used also in swimming to estimate anaerobic metabolism. The AOD precision may be assessed for each individual and exercise condition, thus providing information on the accuracy of the method. The main methodological issue behind the AOD method is the establishment of the $\dot{V} \mathrm{O}_{2} /$ exercise intensity relationship with steady-state measurement of $\dot{V} \mathrm{O}_{2}$ at several intensities. Therefore, the method requires the use of exercise bouts with a duration that enables the steady-state attainment. Assessing $\dot{V} \mathrm{O}_{2}$, some authors (Troup 1991; Klentrou and Montpetit 1992) used bouts of more than $4 \mathrm{~min}$, while others carried out their studies based on the measurements conducted between the third and fourth minutes of exercise (Takahashi et al. 1983).

Few have reported the analysis of the AOD from respiratory measurements during crawl swimming performed by males (Faina et al. 1997; Ogita et al. 1999; Silva et al. 2006; Zoeller et al. 2000). But, to our knowledge, no study on breaststroke is available. Research on breaststroke swimming has been mainly focused on kinematics (Thompson et al. 2004), but there are also a number of studies addressing $C_{\mathrm{S}}$ estimations based on $\dot{V} \mathrm{O}_{2}$ measurements (Barbosa et al. 2008) combined with estimations of anaerobic energy release through blood lactate measurements (Capelli et al. 1998).

Therefore, the use of the AOD to quantify the anaerobic energy release at different breaststroke swimming distances seems interesting. However, since no study on the precision of the AOD estimation in swimming is available, it is necessary to assess the reliability of the method before interpreting AOD values.

The present study intended to investigate the AOD method in breaststroke swimming. The aims of the study were: (a) to assess the reliability of the oxygen uptake/ swimming velocity regression line in breaststroke swimming, (b) to assess the reliability of the linear extrapolation of supra-maximal oxygen demand from the oxygen uptake/ swimming velocity regression line in Crawl swimming and (c) to quantify the precision of the AOD in supra-maximal breaststroke swimming.

\section{Methods}

Participants

Sixteen male swimmers volunteered after medical approval and gave informed consent to participate in the present study. All subjects were involved in systematic training and competition programs (from 9 to 12 weekly training sessions) and participated regularly in swimming Crawl events. The mean $( \pm 1 \mathrm{SD})$ of their age, height, arm span, body mass and estimated fat percentage was $16.9 \pm 2.8$ years, $1.78 \pm 0.05 \mathrm{~m}$, $1.86 \pm 0.06 \mathrm{~m}, 69.7 \pm 9.0 \mathrm{~kg}$ and $11.6 \pm 2.3 \%$, respectively. The swimmers' personal best performances at the time of the measurements in the 100 and $200 \mathrm{~m}$ in short course (25-m swimming pool) were $70.20 \pm 5.02$ and $153.67 \pm 10.4 \mathrm{~s}$, respectively.

\section{Experimental design}

The experimental testing was conducted in an indoor $25-\mathrm{m}$ swimming pool. During the 5 days prior to the experiment, the subjects were not engaged in high-intensity training sessions and limited their training program to a single daily low-intensity swimming session. The subjects performed two swimming tests in different days, with a 24-h recovery between tests: a graded swimming test and an all-out test. Both tests were conducted in the morning (between 10.00 and 12.00 a.m.), with a room temperature of $25-28^{\circ} \mathrm{C}$ and with a humidity of $50-60 \%$. In the first day of testing, before the graded test, anthropometric measurements were performed. All the procedures were in accordance with the Helsinki Declaration of 1975 and were approved by the Institutional Ethics Committee.

\section{Procedures}

\section{Anthropometric measurements}

A stadiometer with a range scale of $0.10 \mathrm{~cm}$ was used for the evaluation of height and a standard scale weighing machine was used to assess body mass. Skin folds were taken with a skin fold caliper Slim Guide (Creative Health Products, USA) to estimate fat percentage (Faulkner 1968).

\section{Graded and intermittent test}

The first test included several exercise bouts at a constant speed. Distance in the two-first bouts was $250 \mathrm{~m}$ and it was $300 \mathrm{~m}$ from the third bout on. Initial velocity was established according to the swimmers' individual performance in the 300-m breaststroke -5 increments of velocity. The increments were $10 \%$ of the $300-\mathrm{m}$ best performance velocity per each $300-\mathrm{m}$ stage until exhaustion. 
The performance if the 300-m breaststroke was estimated taking into account the performance if the 100 and 200-m breaststrokes:

$$
\begin{aligned}
& v 300=v 200-(v 200-v 400) / 2 \\
& v 400=(7 \times v 200 / 4)-(3 \times v 100 / 4)
\end{aligned}
$$

where $v 100$ and $v 200$ represent the velocity of the 100- and $200-\mathrm{m}$ breaststroke events and $v 300$ and $v 400$ represent the estimation of the velocity of the 300- and 400-m breaststroke events.

During this test the swimming speed of the subjects was kept constant by an electronic pacer, with successive flashing lights, placed at the bottom of the pool (TAR. 1.1, GBK-electronics, Aveiro, Portugal). The subjects were instructed to follow the pacer light signal. No warmup was performed before the start of the test and recovery between successive bouts was individualized. The subjects started each bout when their $\dot{V} \mathrm{O}_{2}$ presented two consecutive values within $2 \mathrm{ml} \mathrm{kg}^{-1} \mathrm{~min}^{-1}$ from that recorded before the start of the first bout (average $\dot{V} \mathrm{O}_{2}$ during second minute prior to the start of the first bout of the graded test). The test was started with the subjects inside the pool (after the signal the subjects pushed-off the wall with their feet and started to swim). Every $25 \mathrm{~m}$ the turn-over was performed with a body rotation without diving and subsequent feet push-off in the wall. Through all testing, expired gases were collected breath by breath and analysed with a K4b2 Gas Analyser (Cosmed, Rome, Italy) connected to an AquaTrainer Valve (Cosmed, Rome, Italy). $\dot{V} \mathrm{O}_{2}$ was averaged for 20-s intervals. Before each test, a reference air calibration of the device was performed using a gas sample with a $16 \% \mathrm{O}_{2}$ concentration and a $5 \% \mathrm{CO}_{2}$ concentration. The flow meter was also calibrated before each testing with a $3,000 \mathrm{ml}$ syringe. The graded test ended by subject's voluntary exhaustion or until they could no longer swim at the predetermined pace. Immediately after the conclusion of each bout, capillary blood samples were collected from the finger to determine the blood lactate concentration with an Accusport device (Boehringer, Manheim, Germany). Before each test a calibration of the Accusport was performed with several YSI 1530 Standard Lactate Solutions $\left(2,4,8\right.$ and $\left.16 \mathrm{mmol}^{-1}\right)$.

\section{All-out test}

The second test consisted of an all-out swimming test. The all-out test was performed in one of the two distances: $100 \mathrm{~m}(n=7)$ and $200 \mathrm{~m}(n=9)$. Subjects were assigned to each distance according to their best performance and were asked to swim as if they were in a timed competition race. Subjects were allowed to perform their regular competition warm-up procedures. However, the test was not started until the subjects' $\dot{V} \mathrm{O}_{2}$ returned to resting values (the same individual value recorded for each subject before the start of the graded test). Each subject performed the test individually. The start of the test and each turn-over were performed as described in the graded test. Throughout the test $\dot{V} \mathrm{O}_{2}$ was also measured with the $\mathrm{K} 4 \mathrm{~b} 2$ Gas Analyser attached to the AquaTrainer and then averaged as $20 \mathrm{~s}$ intervals. The aforementioned calibration procedures were also performed before each test. In addition, capillary blood sample collections were made every 2 -min post-race until blood lactate concentration levelled off.

\section{Data analysis}

The graded test was performed to obtain $\dot{V} \mathrm{O}_{2}$ /velocity relation points that enabled the calculation of a valid regression equation. Peak $\dot{V} \mathrm{O}_{2}$ was the highest 20-s average $\dot{V} \mathrm{O}_{2}$ value observed in each subject either in the graded or in the all-out tests. Swimming velocity associated with peak $\dot{V} \mathrm{O}_{2}$ was estimated from the inclusion of the peak $V \mathrm{O}_{2}$ of each subject in the individual $\dot{V} \mathrm{O}_{2} /$ velocity regression equation. The $\dot{V} \mathrm{O}_{2} /$ velocity regression was developed for each subject using the steady-state $\dot{V} \mathrm{O}_{2}$ values during the last min of each exercise bout in the graded test. An individual resting $\dot{V} \mathrm{O}_{2}$ measurement (zero speed $\dot{V} \mathrm{O}_{2}$ ) was also included in the regressions. Oxygen uptake measurements from incomplete bouts (less than $300 \mathrm{~m}$ ) were not included in the regression. Additionally, bouts that failed to comply with the $\dot{V} \mathrm{O}_{2}$ steadystate attainment (given by a difference less than $2 \mathrm{ml} \mathrm{kg}{ }^{-1} \min ^{-1}$ between two consecutive minutes) were also not included in the regressions.

The $C_{\mathrm{S}}$ was determined from the slope of the $\dot{V} \mathrm{O}_{2} /$ velocity regression line. Accumulation of blood lactate in the graded test was traced by linear interpolation to determine the swimming velocity corresponding to the $4 \mathrm{mmol} \mathrm{l}^{-1}$ threshold.

The AOD was calculated as the difference between total energy demand (TED) and accumulated $\dot{V} \mathrm{O}_{2}\left(\dot{V} \mathrm{O}_{2} \mathrm{Ac}\right)$ during the all-out tests. This estimation was not corrected for body oxygen stores. TED was calculated by linear extrapolation and $\dot{V} \mathrm{O}_{2} \mathrm{Ac}$ was the integration of $\dot{V} \mathrm{O}_{2}$ during the all-out test over the time. The imprecision of the AOD ( $\mathrm{AOD}^{\text {error }}$ ) was calculated as follows (Reis et al. 2004):

$$
\mathrm{AOD}^{\text {error }}=\sqrt{ }\left(\text { error for total } \mathrm{ED}^{2}+\text { error for } \dot{V} \mathrm{O}_{2} \mathrm{Ac}^{2}\right)
$$

where

error for total $\mathrm{ED}=$ error for $\mathrm{ED} \times$ duration 
and

error for $\dot{V} \mathrm{O}_{2} \mathrm{Ac}=$ error for $\dot{V} \mathrm{O}_{2} \times$ duration.

The error for ED is given by the standard error of the predicted value for the energy demand. The error for $\dot{V} \mathrm{O}_{2}$ was assumed to be 3\% (Robergs and Burnett 2003).

\section{Statistics}

Data were analysed with SPSS 14.0 (SPSS Science, Chicago, USA). Linear regression was used on all appropriate data. The scatter around the regression line (Syx) was used to assess the reliability of the regression lines. The standard error of the predicted value (SEP) was used to assess the reliability of the linear extrapolation of the energy cost of swimming. Differences between groups of subjects were assessed with one-way ANOVA and Scheffe post hoc, after normality assumption was verified with the Shapiro-Wilk test. Simple bivariate correlations between variables were investigated with the Pearson productmoment coefficient, taking values from the whole sample. The statistical significance was set to $P \leq 0.05$. The results are presented as mean \pm SD.

\section{Results}

All subjects completed four sub-maximal bouts with a duration comprised between $5 \mathrm{~min}$ and $6 \mathrm{~min} 30 \mathrm{~s}$, where $\dot{V} \mathrm{O}_{2}$ achieved a steady-state. The first three bouts were performed at intensity below the $4 \mathrm{mmol}^{-1}$ lactate threshold and the fourth bout above this threshold. Figure 1 shows a typical $\dot{V} \mathrm{O}_{2}$ on-kinetics pattern for one subject in the four sub-maximal bouts and Fig. 2 depicts the regression lines from steady-state $\dot{V} \mathrm{O}_{2}$ and swimming velocity in

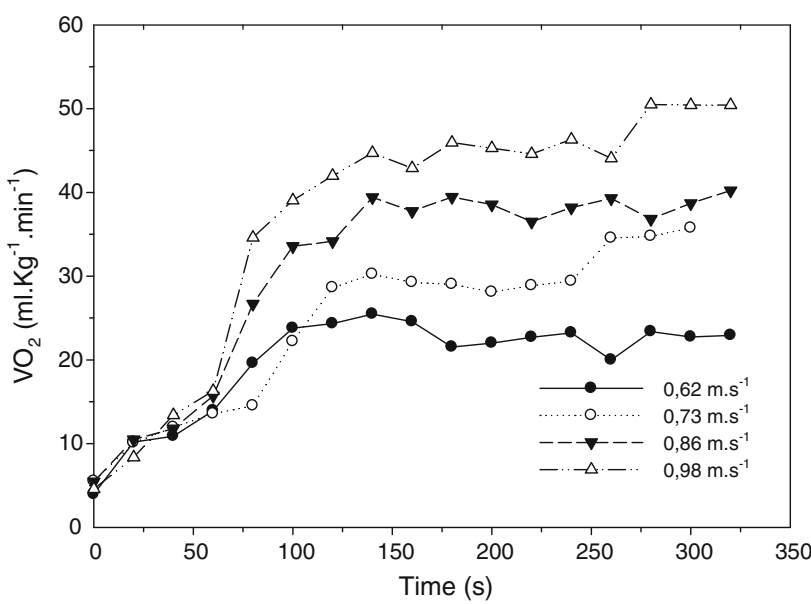

Fig. $1 V \mathrm{O}_{2}$ on-kinetics pattern for one subject in the four submaximal bouts

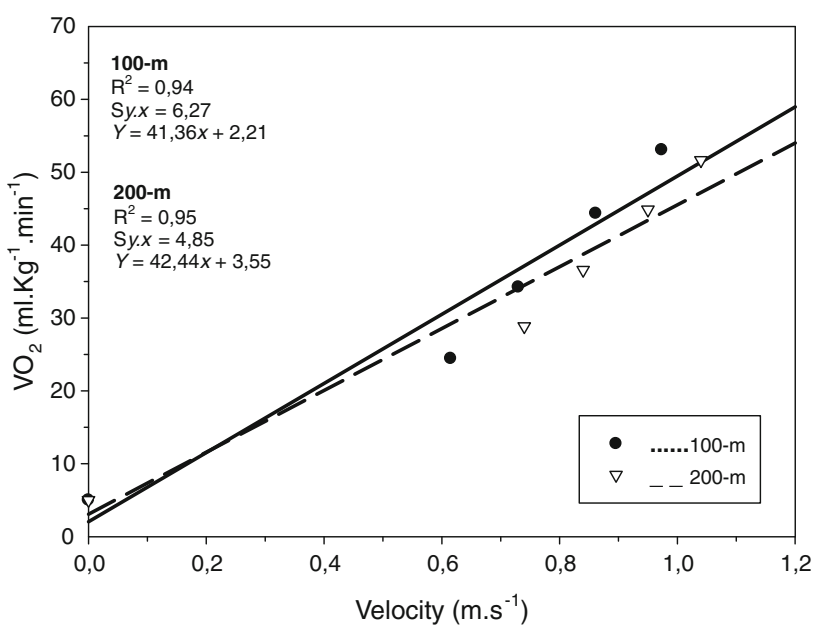

Fig. 2 Regression lines $\left(\mathrm{VO}_{2}\right.$ as function of swimming velocity in the graded test) in the two groups of subjects

the two groups of subjects. Some subjects were engaged in a fifth bout to attain voluntary exhaustion, but all these failed to conclude the full bout. Mean $( \pm S D)$ values for blood lactate and relative intensity expressed as peak $\dot{V} \mathrm{O}_{2}$ percentage were, respectively, in the four sub-maximal bouts: $2.10 \pm 0.65 \mathrm{mmol}^{-1}$ and $42.87 \pm 15.53 \%$, $2.15 \pm 0.86 \mathrm{mmol} \mathrm{l}^{-1}$ and $58.97 \pm 14.38 \%, \quad 3.61 \pm$ $2.52 \mathrm{mmol} \mathrm{l}^{-1}$ and $73.37 \pm 10.79 \%, 5.41 \pm 2.94 \mathrm{mmol} \mathrm{l}^{-1}$ and $78.46 \pm 24.29 \%$.

Peak $\dot{V} \mathrm{O}_{2}$ was $61.75 \pm 9.05 \mathrm{ml} \mathrm{kg}^{-1} \min ^{-1}$ in the overall sample, with an higher (non-significant) value in the $100-\mathrm{m}$ swimmers' group $\left(65.28 \pm 11.36 \mathrm{ml} \mathrm{kg}^{-1} \mathrm{~min}^{-1}\right)$ when compared with the $200-\mathrm{m}$ group $\left(59.01 \pm 6.13 \mathrm{ml} \mathrm{kg}^{-1}\right.$ $\left.\min ^{-1}\right)$. The $C_{\mathrm{S}}$ was $0.777 \pm 0.09$ and $0.707 \pm 0.09 \mathrm{ml}$ $\mathrm{kg}^{-1} \mathrm{~m}^{-1}$, respectively, in the 100 and 200-m groups (non-significant differences). Peak $\dot{V} \mathrm{O}_{2}$ and $C_{\mathrm{S}}$ were positively correlated $(r=0.56, P<0.05)$. The $C_{\mathrm{S}}$ was also significantly correlated with AOD $(r=0.73, P<0.01)$ and

Table 1 Measurements and calculations in the two all-out bouts $($ mean \pm SD)

\begin{tabular}{|c|c|c|}
\hline & $100 \mathrm{~m}(n=7)$ & $200 \mathrm{~m}(n=9)$ \\
\hline $\operatorname{VEL}\left(\mathrm{m} \mathrm{s}^{-1}\right)$ & $1.18 \pm 0.11$ & $1.13 \pm 0.06$ \\
\hline ANAER (\%) & $27.31 \pm 11.57$ & $14.26 \pm 8.87 \gamma$ \\
\hline $\mathrm{AOD}\left(\mathrm{ml} \mathrm{kg}^{-1}\right)$ & $22.20 \pm 12.25$ & $23.09 \pm 15.55$ \\
\hline $\operatorname{SEP}\left(\mathrm{ml} \mathrm{kg}^{-1} \min ^{-1}\right)$ & $5.51 \pm 0.95$ & $3.52 \pm 1.46$ \\
\hline $\mathrm{CI} 95 \%\left(\mathrm{ml} \mathrm{kg}^{-1} \min ^{-1}\right)$ & $30.05 \pm 7.88$ & $22.96 \pm 13.03$ \\
\hline $\mathrm{AOD}^{\text {error }}\left(\mathrm{ml} \mathrm{kg}^{-1}\right)$ & $7.88 \pm 1.07$ & $10.13 \pm 3.22$ \\
\hline Peak BL $\left(\mathrm{mmol} \mathrm{l}^{-1}\right)$ & $11.67 \pm 3.01$ & $8.72 \pm 1.57 \gamma$ \\
\hline
\end{tabular}

$V E L$ average swimming velocity, ANAER anaerobic fraction of energy release, $A O D$ accumulated oxygen deficit, $S E P$ standard error of the predicted energy cost, $95 \%$ CI $95 \%$ confidence interval of the predicted energy cost, $A O D^{\text {error }}$ estimation error of AOD, Peak $B L$ peak blood lactate post-exercise

$\gamma$ : different from $100 \mathrm{~m}(P<0.05)$ 
with ANAER $(r=0.73, P<0.01)$. Table 1 presents measurements and calculations in the two all-out bouts that were performed.

\section{Discussion}

The present study intended to investigate the AOD method in breaststroke swimming. The main findings of the present study were that the reliability of oxygen uptake/swimming velocity regression lines was acceptable (with standard errors of $\approx 5-6 \mathrm{ml} \mathrm{kg}^{-1} \mathrm{~min}^{-1}$ ), though better in the $200 \mathrm{~m}$. The AOD imprecision varied among the two distance events from $\approx 7$ to $10 \mathrm{ml} \mathrm{kg}^{-1}$ errors.

The use of the $\dot{V} \mathrm{O}_{2}$ /exercise intensity regression to estimate $C_{\mathrm{S}}$ is present in the literature for crawl (Barbosa et al. 2006; Kjendlie et al. 2004; Ogita et al. 1999), but much scarcely for breaststroke swimming (Barbosa et al. 2008). Barbosa et al. (2008) established the regression by measuring the $\dot{V} \mathrm{O}_{2}$ during increasing intensity 200-m submaximal bouts with a $30 \mathrm{~s}$ recovery between them and the authors report a steady-state attainment. Indeed, the main assumption to use the oxygen uptake/exercise intensity regression line to estimate the energy cost is the establishment of steady-state sub-maximal $\dot{V} \mathrm{O}_{2}$ at several exercise intensities. Our subjects completed four full submaximal bouts with a duration comprised between $5 \mathrm{~min}$ and $6 \mathrm{~min} 30 \mathrm{~s}$, where $\dot{V} \mathrm{O}_{2}$ achieved a steady-state (see Fig. 1). In the first and third bouts, $\dot{V} \mathrm{O}_{2}$ attained a steadystate within the first $2 \mathrm{~min} 30 \mathrm{~s}$ of exercise. However, in the second and fourth bouts, though an apparent steadystate was present at $150 \mathrm{~s}$ of exercise, beyond the fourth, an increase in $\dot{V} \mathrm{O}_{2}$ was evident. The first three bouts were performed at intensity below $75 \%$ of subjects' peak $\dot{V} \mathrm{O}_{2}$ and with a blood lactate less than $3 \mathrm{mmol}^{-1}$ and the fourth bout, which was performed at a relative intensity of $88.75 \pm 10.24 \%$ peak $\dot{V} \mathrm{O}_{2}\left(5.63 \pm 3.06 \mathrm{mmol} \mathrm{l}^{-1}\right)$.

Another assumption which is necessary to establish accurately the $\dot{V} \mathrm{O}_{2}$ /exercise intensity relationship is that the various sub-maximal efforts are viewed as independent bouts of exercise. This means that no exercise bout should start until the subject's $\dot{V} \mathrm{O}_{2}$ lowers to a resting $\dot{V} \mathrm{O}_{2}$. We used this criterion in our graded test. Previous studies on both crawl (Barbosa et al. 2006) and breaststroke swimming (Barbosa et al. 2008) used 30-s recovery periods between exercise bouts, which in our opinion is too short to allow $\dot{V} \mathrm{O}_{2}$ to return to resting value.

In the present study, it was possible to observe in most of the subjects an apparent $\dot{V} \mathrm{O}_{2}$ steady-state (given by a variation less than $2 \mathrm{ml} \mathrm{kg}^{-1} \min ^{-1}$ ) in the last minute of exercise. However, the fact that $\dot{V} \mathrm{O}_{2}$ mean values over the last minute of exercise were $\approx 350 \mathrm{ml} \mathrm{min}{ }^{-1}$ higher than the value recorded at the third minute, it is possible that a true slow component was present (Reis et al. 2007) and that $\dot{V} \mathrm{O}_{2}$ could still have raised more if the exercise bout was prolonged. Others have also found similar $\dot{V} \mathrm{O}_{2}$ slow component mean values in crawl swimming (Demarie et al. 2001; Fernandes et al. 2008), but we could not find in the literature such phenomena described in breaststroke swimming. The fact that breaststroke $C_{\mathrm{S}}$ is higher when compared with crawl swimming (Capelli et al. 1998; Reis et al. 2006) may partly help to explain the $\mathrm{O}_{2}$ drift that we

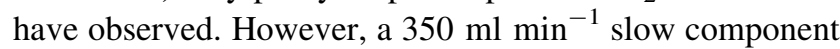
at exercise intensity below the $4 \mathrm{mmol}^{-1}$ lactate threshold is still surprising. These results may indicate that the analysis of $C_{\mathrm{S}}$ based on $\dot{V} \mathrm{O}_{2}$ measurements during breaststroke warrants special attention to the gas kinetics and advices the use of longer durations of sub-maximal bouts in testing (6 min or more).

In the present study, $C_{\mathrm{S}}$ was $0.777 \pm 0.09$ and $0.707 \pm 0.09 \mathrm{ml} \mathrm{kg}^{-1} \mathrm{~m}^{-1}$, respectively, in the 100 and $200 \mathrm{~m}$ groups (non-significant differences). Peak $\dot{V} \mathrm{O}_{2}$ was also higher (non-significant) in the 100-m swimmers' group $\left(65.28 \pm 11.36 \mathrm{ml} \mathrm{kg}^{-1} \mathrm{~min}^{-1}\right)$ when compared with the $200-\mathrm{m}$ group $\left(59.01 \pm 6.13 \mathrm{ml} \mathrm{kg}^{-1} \min ^{-1}\right)$. Hence, the higher peak $\dot{V} \mathrm{O}_{2}$ in the 100 -m swimmers may explain the larger energy cost in this group. In fact, the two measures were positively correlated in the present study $(r=0.56$, $P<0.05)$. The mean values of $C_{\mathrm{S}}$ in the present study are lower when compared with our previous observation (Reis et al. 2006) in a group of breaststroke swimmers with a peak $\dot{V} \mathrm{O}_{2}$ similar to that of the 100-m group in the present study. Additionally, our mean values for $C_{\mathrm{S}}$ are comprised between the observations of Barbosa et al. (2008) and those by Capelli et al. (1998) during breaststroke swimming. The lower mean value by Barbosa et al. (2008) reported at a swimming velocity of $1.00 \mathrm{~m} \mathrm{~s}^{-1}$ can be explained by the fact that the sample included male and female swimmers. Otherwise, in the present study and in that by Capelli et al. (1998), only males were assessed. Our subjects exercised at velocities comprised between 0.62 and $1.10 \mathrm{~m} \mathrm{~s}^{-1}$ in the graded test and the method that was used (linear regression) is not sensitive to potential changes in $C_{\mathrm{S}}$ across different velocities. Contrarily, the data from Capelli et al. (1998) indicated that $C_{\mathrm{S}}$ could vary between 0.66 and $0.87 \mathrm{ml} \mathrm{kg}^{-1} \mathrm{~m}^{-1}$ across swimming velocities ranging from 0.79 to $1.09 \mathrm{~m} \mathrm{~s}^{-1}$. The fact that our calculations included only the $\dot{V} \mathrm{O}_{2}$ measurement may explain the lower mean values, when compared to that by Capelli et al. (1998). Indeed, these authors added the anaerobic energy release estimations to the $\dot{V} \mathrm{O}_{2}$ measured during the exercise.

In the present study, although the performance level of the subjects in the two groups was not significantly different, it is true that different subjects swimming with different technical patterns may influence the variables that were assessed. Therefore, the comparisons between the 
responses in the two groups do not reflect necessarily what could result from a true comparative study (with the same subjects swimming the two distance events).

The linearity of the scatter was high in the two groups of subjects and the standard error of estimate $\approx 5$ $6 \mathrm{ml} \mathrm{kg}{ }^{-1} \min ^{-1}$. We could not find in the literature studies with similar subject cohort that provided information on this type of regression reliability in swimming exercise. When the individual regression lines were used to extrapolate the energy demand in the all-out bouts, we found a lower mean value in the 200-m bout $(3.52 \pm 1.46$ vs. $5.51 \pm 0.95 \mathrm{ml} \mathrm{kg}^{-1} \mathrm{~min}^{-1}$ ). Despite the large $95 \%$ confidence intervals of the prediction in both distances (above $20 \mathrm{ml} \mathrm{kg}^{-1} \mathrm{~min}^{-1}$ ), the relative error of the prediction was acceptable in the $200 \mathrm{~m}(\approx 6 \%)$, though worst in the $100 \mathrm{~m}(\approx 9 \%)$. However, in running and cycling exercise, others have reported lower errors of the predicted value (Reis et al. 2005; Russell et al. 2000).

The AOD has been vastly used to quantify anaerobic energy release during exercise in different physical activities, especially in running (Bickham et al. 2002; Duffield et al. 2004; Reis et al. 2004). It has been rarely used in crawl swimming (Ogita et al. 1999), and to our knowledge, no study on breaststroke is available. In the present study, we found AOD mean values of $22.20 \pm 12.25$ and $23.09 \pm 15.55 \mathrm{ml} \mathrm{kg}{ }^{-1}$, respectively, in the 100 - and $200-\mathrm{m}$ all-out bouts. These values are lower than those by Ogita et al. (1999) for supra-maximal 2-3 min crawl in the swimming flume. The ANAER in the present study was $\approx 27 \%$ in the 100 -m bout and $\approx 14 \%$ in the 200 -m bout. Despite the absence of studies on the AOD during pool swimming, other approaches have been used to quantify the anaerobic energy release in real or simulated competitions performed by swimmers. Indeed, estimations from postexercise BL, and assumptions for alactic energy (Capelli et al. 1998), pointed out to higher values of ANAER for the 200-m distance, compared to those in the present study.

During supra-maximal running it has been demonstrated that AOD attains a maximal value between 2 and $3 \mathrm{~min}$ of treadmill exhaustive exercise (Medbø et al. 1988). We found similar AOD in the two distances, where exercise time was $\approx 1 \min 24 \mathrm{~s}$ and $\approx 2 \min 56 \mathrm{~s}$, respectively, in 100 - and 200-m bouts. If the values that we observe could represent the subjects maximal AOD, then we have to conclude that in breaststroke swimming the maximal AOD may be attained in less than $2 \mathrm{~min}$. In the future it may be interesting to assess the swimmers' response during a 50-m all-out bout to confirm if AOD is larger than our observations. Anyway, it is our opinion that the nature of swimming exercise itself (liquid environment and low frequency of movement, as compared with all-out running) may prevent maximal AOD to appear during this type of activity.
In the present study, the error of AOD estimation was lower (though non-significant) in the $100 \mathrm{~m}(7.88 \pm$ $1.07 \mathrm{ml} \mathrm{kg}^{-1}$ ) when compared with that calculated for the $200-\mathrm{m}$ bout $\left(10.13 \pm 3.22 \mathrm{ml} \mathrm{kg}^{-1}\right)$. Since the AOD values that were assessed in the two distances were similar, the relative error is smaller for the $100-\mathrm{m}$ event. In the literature, we have not found a single reference to the AOD error in swimming. Therefore, we have only previous references from other types of exercise (i.e. running), which are typically $\approx 4-5 \mathrm{ml} \mathrm{kg}^{-1}$ (Medbø et al. 1988; Reis et al. 2005). These confrontations suggest that the precision of AOD in the present study may be considered as poor.

\section{Conclusions}

Since the AOD variability and relative errors observed in this study were high, the AOD method may not be accurate in Breaststroke swimming at high-intensities. This may be due to the potential effect of an increased contribution of pressure and wave drag result in an exponential increase in total drag at high speeds. At these speeds the linear extrapolation of energy cost from sub-maximal to supramaximal velocities may not be accurate. The oxygen uptake/swimming velocity regression lines allowed an extrapolation of CS to higher intensities with a high mathematical precision (standard errors of prediction of $\approx 3-6 \mathrm{ml} \mathrm{kg}^{-1} \mathrm{~min}^{-1}$ ); however, the swimmers' physiological responses during the high-intensity bout suggest that mechanical factors (i.e. wave drag) may have altered the linearity that was observed at sub-maximal intensities.

Acknowledgments This investigation was supported by grants of Fundação para a Ciência e Tecnologia (FCT-POCI/DES/58362/2004). All the experiments herein comply with the current laws of the country in which they were performed.

Conflict of interest statement The authors declare that they have no conflict of interest.

\section{References}

Barbosa TM, Fernandes R, Keskinen KL, Colaço P, Cardoso C, Silva J, Vilas-Boas JP (2006) Evaluation of the energy expenditure in competitive swimming strokes. Int J Sports Med 27:894-899

Barbosa TM, Fernandes R, Keskinen KL, Vilas-Boas JP (2008) The influence of stroke mechanics into energy cost of elite swimmers. Eur J Appl Physiol 103:139-149

Bickham D, Le Rossignol P, Gibbons C, Russell AP (2002) Re-assessing accumulated oxygen deficit in middle-distance runners. J Sci Med Sport 5:336-340

Capelli C, Pendergast DR, Termim B (1998) Energetics of swimming at maximal speeds in humans. Eur J Appl Physiol 78:385-393

Demarie S, Sardella F, Billat V, Magini W, Faina M (2001) The $V_{2}$ slow component in swimming. Eur J Appl Physiol 84:95-99 
diPrampero P, Pendergast D, Wilson D, Rennie D (1978) Blood lactacid acid concentrations in high velocity swimming. In: Eriksson B, Furberg B (eds) Swimming medicine IV. University Park Press, Baltimore, pp 249-261

Duffield R, Dawson B, Goodman C (2004) Energy system contribution to $100-\mathrm{m}$ and $200-\mathrm{m}$ track running events. J Sci Med Sport 7:302-313

Faina M, Billat V, Squadrone R, de Angelis M, Koralsztein J, Dal Monte A (1997) Anaerobic contribution to the time to exhaustion at the minimal exercise intensity at which oxygen uptake occurs in elite cyclists, kayakists and swimmers. Eur J Appl Physiol 76:13-20

Faulkner JA (1968) New perspectives in training for maximum performance. J Am Med Assoc 205:741-746

Fernandes RJ, Keskinen KL, Colaço P, Querido AJ, Machado LJ, Morais PA, Novais DQ, Marinho DA, Vilas-Boas JP (2008) Time limit at $V \mathrm{O}_{2 \max }$ velocity in elite crawl swimmers. Int $\mathrm{J}$ Sports Med 29:145-150

Kjendlie PL, Ingjer F, Madsen O, Stallman RK, Stray-Gundersen J (2004) Differences in the energy cost between children and adults during front crawl swimming. Eur J Appl Physiol 91:473480

Klentrou PP, Montpetit RR (1992) Energetics of backstroke swimming in males and females. Med Sci Sports Exerc 24:371-375

Medbø J, Mohn A, Tabata I, Bahr R, Vaage O, Sejersted O (1988) Anaerobic capacity determined by maximal accumulated $\mathrm{O}_{2}$ deficit. J Appl Physiol 64:50-60

Ogita F, Onodera T, Tabata I (1999) Effect of hand paddles on anaerobic energy release during supramaximal swimming. Med Sci Sports Exerc 31:729-735

Reis VM, Duarte JA, Espírito-Santo J, Russell AP (2004) Determination of accumulated oxygen deficit during a $400 \mathrm{~m}$ run. J Exerc Physiol 7:77-83

Reis VM, Silva AJ, Ascensão A, Duarte JA (2005) Inclusion of exercise intensities above the lactate threshold in $\mathrm{O}_{2} /$ running speed regression does not improve the precision of accumulated oxygen deficit estimation in endurance-trained runners. J Sports Sci Med 4:455-462

Reis V, Silva AJ, Reis A, Garrido N, Moreira A, Carneiro A, Marinho D, Neto $S$ (2006) Assessment of sub maximal and supra maximal swimming energy cost in crawl and breaststroke swimmers. In: Vilas-Boas JP, Alves F, Marques A (eds) Book of abstracts of the Xth biomechanics and medicine in swimming. Port J Sport Sci 6:(Suppl 1):55-56

Reis VM, Guidetti L, Duarte JA, Ascensão A, Silva AJ, Sampaio JE, Russell AP, Baldari C (2007) Slow component of $V_{2}$ during level and uphill treadmill running: relationship to aerobic fitness in endurance runners. J Sports Med Phys Fitness 47:135-140

Robergs RA, Burnett AF (2003) Methods used to process data from indirect calorimetry and their application to $\mathrm{VO}_{2} \max$. $\mathrm{J}$ Exerc Physiol 6:44-57

Russell AP, Rossignol P, Lo S (2000) The precision of estimating the total energy demand: implications for the determination of the accumulated oxygen deficit. J Exerc Physiol 3:55-63

Russell AP, Rossignol P, Snow R, Lo S (2002) Cycling at 120 when compared to $80 \mathrm{rev} / \mathrm{min}$ increases the accumulated oxygen deficit but does not affect the precision of its calculation. J Exerc Physiol 5:32-38

Silva A, Reis VM, Reis A, Garrido N, Moreira A, Carneiro A, Alves F (2006) Associations between energy release and performance in a supramaximal effort of $200 \mathrm{~m}$ in crawl. In: Vilas-Boas JP, Alves F, Marques A (eds) Book of abstracts of the Xth biomechanics and medicine in swimming. Port $\mathrm{J}$ Sport Sci 6(Suppl 1):59-60

Takahashi G, Nomura T, Yoshida A, Miyashita M (1983) Physiological energy consumption during swimming, related to added drag. In: Matsui H, Kobayashi K (eds) Biomechanics VIIIB. Human Kinetics Publishers, Illinois, pp 842-847

Thompson KG, MacLaren DP, Lees A, Atkinson G (2004) The effects of changing pace on metabolism and stroke characteristics during high-speed breaststroke swimming. J Sport Sci 22:149157

Troup J (1991) Aerobic characteristics of the four competitive strokes. In: Troup J (ed) International Center for Aquatic Research Annual: studies by the International Center for Aquatic Research (1990-1991). US Swimming Press, Colorado Spring, pp 3-7

Zamparo P, Capelli C, Cautero M, Di Nino A (2000) Energy cost of front crawl swimming at supra-maximal speeds and underwater torque in young swimmers. Eur J Appl Physiol 83:487-491

Zoeller R, Nagle E, Robertson R, Moyna N, MLephart S, Goss F (2000) Peak blood lactate and accumulated oxygen deficit as indices of freestyle swimming performance in trained adult female swimmers. J Swim Res 14:18-25 